\title{
Viagem educacional e oficinas temáticas como ferramentas de formação construtivista em psicofarmacologia clínica
}

\author{
Educational journey and thematic workshops as a constructivist training \\ tools in clinical psychopharmacology
}

\section{Viaje educativo y talleres temáticos como herramientas de formación constructivista en psicofarmacología clínica}

\author{
Mússio Pirajá Mattos ${ }^{1, a}$ \\ mussiopiraja@hotmail.com | https://orcid.org/0000-0002-8792-5860 \\ ${ }^{1}$ Universidade Federal do Oeste da Bahia, Centro das Ciências Biológicas e da Saúde. Barreiras, BA, Brasil. \\ a Mestrado em Ciências Farmacêuticas pela Universidade Federal da Bahia.
}

\section{Resumo}

O construtivismo é uma teoria que permite conceber o conhecimento como algo que não é dado e sim construído, através de sua ação e da interação com o meio. Trata-se de um relato de experiência do uso da viagem educacional e oficinas temáticas no componente curricular psicofarmacologia clínica, como ferramentas de formação construtivista em saúde. A viagem educacional permitiu a integração emoçãorazão a partir dos significados percebidos em contato com produções artísticas. A clínica tornou-se ampliada no cuidado a partir da prática biopsicossocial, da humanização e do desenvolvimento da inteligência emocional. As oficinas temáticas proporcionaram aprendizagens complexas e produção de dispositivos que permitiram a vivência do acolhimento, vínculo, comunicação, sensibilidade e empatia entre os sujeitos. A utilização dessas ferramentas foi assertiva por estimular a formação por meio de competências, interdisciplinaridade e aprendizagem significativa, além de tornar o ambiente em sala de aula agradável e contribuir para construção de um perfil profissional que cria permanentemente.

Palavras-chave: Filmes cinematográficos; Comunicação interdisciplinar; Educação em Saúde; Psicofarmacologia; Metodologia ativa. 


\begin{abstract}
The constructivism is a theory that allows us to conceive of knowledge as something that is not given but constructed through its action and interaction with the environment. This is an experience report of the use of educational journey and thematic workshops in the clinical psychopharmacology curriculum component as constructivist training tools in health. The educational journey allowed the integration of emotionreason from the meanings perceived in contact with artistic productions. The clinic has expanded into care from the biopsychosocial practice, the humanization and the development of emotional intelligence. The thematic workshops provided complex learning and production of devices that allowed the experience of the host, bond, communication, sensitivity and empathy between the subjects. The use of these tools was assertive for stimulating the training through skills, interdisciplinarity and meaningful learning, as well as making the classroom environment pleasant and contributing to the construction of a professional profile that creates permanently.
\end{abstract}

Keywords: Motion pictures; Interdisciplinary communication; Health Education; Psychopharmacology; Active methodology.

\title{
Resumen
}

El constructivismo es una teoría que permite concebir el conocimiento como algo que no es dado y sí construido, a través de su acción y de la interacción con el medio. Se trata de un relato de experiencia del uso del viaje educativo y talleres temáticos en el componente curricular psicofarmacología clínica, como herramientas de formación constructivista en salud. El viaje educativo permitió la integración emoción-razón a partir de los significados percibidos en contacto con producciones artísticas. La clínica se ha ampliado en el cuidado a partir de la práctica biopsicosocial, de la humanización y del desarrollo de la inteligencia emocional. Los talleres temáticos proporcionaron aprendizajes complejos y producción de dispositivos que permitieron la vivencia de la acogida, vínculo, comunicación, sensibilidad y empatía entre los sujetos. La utilización de estas herramientas fue asertiva por estimular la formación por medio de competencias, interdisciplinariedad y aprendizaje significativo, además de hacer el ambiente en el aula agradable y contribuir a la construcción de un perfil profesional que crea permanentemente.

Palabras clave: Películas cinematográficas; Comunicación interdisciplinaria; Educación en Salud; Psicofarmacología; Metodología activa.

Contribuição dos autores:

Concepção e desenho do estudo: Mússio Pirajá Mattos.

Aquisição, análise ou interpretação dos dados: Mússio Pirajá Mattos.

Redação do manuscrito: Mússio Pirajá Mattos.

Revisão crítica do conteúdo intelectual: Mússio Pirajá Mattos.

Declaração de conflito de interesses: Este trabalho não apresenta conflito de interesses.

Fontes de financiamento: Não houve.

Considerações éticas: Não há.

Agradecimentos/Contribuições adicionais: Não há.

Histórico do artigo: Submetido: 23.nov.2017 | Aceito: 12.set.2018 | Publicado: 21.dez.2018.

Apresentação anterior: Não houve.

Licença CC BY-NC atribuição não comercial. Com essa licença é permitido acessar, baixar (download), copiar, imprimir, compartilhar, reutilizar e distribuir os artigos, desde que para uso não comercial e com a citação da fonte, conferindo os devidos créditos de autoria e menção à Reciis. Nesses casos, nenhuma permissão é necessária por parte dos autores ou dos editores. 


\section{Introdução}

Há um grande desafio em conceber um ambiente educativo onde trabalhar e formar não se tornem atividades distintas. Nesse sentido, um caminho interessante para transformar o ensino voltado para formação de profissionais que pratiquem a "reflexão a partir da ação" pode ser embasado no construtivismo. O construtivismo ${ }^{1}$ não é uma prática nem um método, e sim uma teoria que permite conceber o conhecimento como algo que não é dado e sim construído, através de sua ação e da interação com o meio. Assim, o construtivismo na educação diferencia-se da transmissão do conhecimento e caracteriza-se como um processo de construção dos saberes. Dessa forma, essa teoria condena a rigidez nos procedimentos de ensino, as avaliações padronizadas e os materiais didáticos alheios à realidade do educando.

$\mathrm{O}$ ensinar exige respeito à autonomia ${ }^{2}$ e à dignidade de cada sujeito, especialmente no âmago de uma abordagem progressiva, alicerce para uma educação que leva em consideração o indivíduo como um ser que constrói a própria história. As metodologias ativas ${ }^{3}$ seguem o princípio teórico significativo da autonomia, no qual a aprendizagem que envolve a autoiniciativa alcança dimensões afetivas e intelectuais, tornando-se mais duradoura e sólida. As metodologias ativas utilizam a problematização como estratégia de ensino-aprendizagem, com o objetivo de alcançar e motivar o educando, pois diante do problema, ele examina, reflete, relaciona sua história e passa a ressignificar suas descobertas. Problemarizar ${ }^{4}$ permite refletir sobre uma situação global de uma realidade concreta, dinâmica, complexa e discutir os conflitos inerentes ao problema.

A formação do psicólogo circunscrita ao modelo dos Parâmetros Curriculares Nacionais (PCN) ${ }^{5}$ é centrada na concepção construtivista de aprendizagem. Nessa perspectiva teórico-metodológica, o currículo deve ser construído tendo em vista a aquisição de competências para a formação e o exercício profissional. Assim, torna-se importante oferecer aos educandos oportunidades de conhecimento e aprendizagem, por meio de ferramentas pedagógicas como a da linguagem cinematográfica, para o desenvolvimento de uma compreensão crítica, reflexiva e com maior tomada de decisão. Esse método é centrado no desempenho do estudante e permite a associação de comportamentos que contribuem para a formação de um perfil profissional baseado na autonomia ${ }^{6}$ que diz respeito a aprender a conhecer, aprender a fazer, aprender a conviver e aprender a ser, garantindo a integralidade da atenção à saúde.

A viagem educacional (VE) é um importante recurso agregador do processo ensino-aprendizagem e exige a presença do facilitador para fomentar e direcionar as discussões acerca do conhecimento proposto. Trata-se de uma ferramenta que permite a integração emoção-razão a partir de sentimentos disparados no contato com a produção artística7 ${ }^{7}$ Assim, as imagens tornam-se um poderoso instrumento de aproximação da realidade, e seu discurso permite a atração dos educandos, sendo possível estimular a reflexão para fins pedagógicos ${ }^{8}$. Empregar filmes como estratégia de formação em saúde ${ }^{9}$ é permitir que o educando reencontre a cultura, o lazer, a ideologia e os valores numa perspectiva ampla e tenha capacidade de relembrar os conhecimentos em sala de aula através de métodos ativos.

Para o ensino da psicofarmacologia, a utilização de filmes tem contribuído para a reflexão e o entendimento de situações clínicas ${ }^{10-12}$. As oficinas temáticas possibilitam a produção de dispositivos didático-pedagógicos que potencializam as habilidades dos educandos e dão suporte ao processo de ensino-aprendizagem. É um lugar de pensar, descobrir, reinventar, criar e recriar, enfim vivenciar ideias, sentimentos e experiências, num movimento de reconstrução individual e coletiva ${ }^{13}$. A utilização dessas ferramentas permite atribuir um enorme potencial pedagógico ${ }^{14}$ por proporcionar aprendizagens mais completas, pois valoriza a construção do conhecimento de forma participativa e questionadora, baseada em situações do cotidiano do educando.

A ideia de realizar o presente trabalho surgiu de uma necessidade pessoal de contribuir com mudanças no processo de formação dos estudantes do curso de psicologia e buscar aprimoramento enquanto profissional 
de educação e saúde, para o qual é necessário refletir continuamente sobre a nossa prática, ampliar os conhecimentos e dialogar com as exigências do processo ensino-aprendizagem atuais. Esse desafio está relacionado com as inquietações e buscas de novas possibilidades de construção didático-pedagógicas, com a intenção de estabelecer estratégias para formar sujeitos capazes de lidar com problemas e propor soluções baseadas nos conhecimentos teórico-práticos oriundos desse processo.

Este artigo refere-se ao relato de experiência como facilitador de metodologias ativas de ensino e aprendizagem, tendo como objetivo relatar a vivência do uso da viagem educacional e oficinas temáticas, no componente curricular psicofarmacologia clínica do curso de graduação em Psicologia, como ferramentas de formação construtivista em saúde.

\section{Metodologia}

Trata-se de um relato de experiência com uso da viagem educacional e oficinas temáticas comoferramentas de formação construtivista em saúde. Os conteúdos teóricos trabalhados foram os psicofármacos para doença de Parkinson, Alzheimer, transtorno do déficit de atenção e hiperatividade (TDAH), depressão, esquizofrenia e drogas de abuso. A seguir, serão explanadas as iniciativas que compuseram as estratégias intervencionistas de educação.

\section{Viagem educacional}

As aulas teóricas iniciaram-se com exposições dialogadas e, posteriormente, a viagem educacional foi utilizada como ferramenta para ampliar a relação ensino-aprendizagem com a construção de novas racionalidades e sentimentos, por meio das interações entre os educandos. A VE ocorreu seguindo os movimentos descritos por Mourthé Junior7 . Assim, realizou-se em primeiro momento, em grande grupo, a exposição das obras cinematográficas (Quadro 1) a fim de disparar sentimentos em contato com a produção artística. Nesse momento, o foco da atividade se concentrou na mobilização das emoções. 
Quadro 1-Obras cinematográficas como ferramenta para mediar o processo educativo

\begin{tabular}{|c|c|c|}
\hline Obras cinematográficas & Diretor & Sinopse \\
\hline Delírios de loucura,1956 & Nicholas Ray & $\begin{array}{l}\text { O professor Ed Avery é diagnosticado com uma rara doença, } \\
\text { que Ihe causa dores terríveis e provavelmente irá matá-lo em } \\
\text { poucos meses. Aconselhado pelos médicos, decide participar } \\
\text { de um tratamento experimental pelo qual é recuperado } \\
\text { milagrosamente. No convívio familiar, Ed faz da vida de sua } \\
\text { esposa e filho um pesadelo sem fim. }\end{array}$ \\
\hline Sem limite, 2011 & Neil Burger & $\begin{array}{l}\text { Eddie utiliza um medicamento revolucionário que permite o uso } \\
\text { de } 100 \% \text { da capacidade cerebral. O efeito é imediato e ele passa } \\
\text { a se lembrar de tudo que já leu, ouviu ou viu em sua vida. }\end{array}$ \\
\hline Geração Prozac, 2001 & Erik Skjoldbjaerg & $\begin{array}{l}\text { Elizabeth Wurtzel é uma brilhante estudante que entra em } \\
\text { profunda depressão. Aos poucos, suas noites de trabalho, } \\
\text { sempre regadas a drogas, e sua instabilidade emocional a } \\
\text { afastam dos amigos e namorado. }\end{array}$ \\
\hline Uma mente brilhante, 2001 & Ron Howard & $\begin{array}{l}\text { John Nash é um gênio da matemática e diagnosticado como } \\
\text { esquizofrênico pelos médicos que dele tratam. Porém, após } \\
\text { anos de luta para se recuperar, ele consegue retornar à } \\
\text { sociedade e acaba sendo premiado com o Nobel. }\end{array}$ \\
\hline Tempo de despertar, 1990 & Penny Marshall & $\begin{array}{l}\text { Malcolm Sayer é um neurologista que conseguiu emprego em } \\
\text { um hospital psiquiátrico. Lá, ele encontra vários pacientes que } \\
\text { aparentemente estão catatônicos, mas Sayer sente que eles } \\
\text { estão somente adormecidos e que, se forem medicados da } \\
\text { maneira correta, poderão ser despertados. }\end{array}$ \\
\hline Para sempre Alice, 2014 & $\begin{array}{l}\text { Richard } \\
\text { Glatzer e Wash } \\
\text { Westmoreland }\end{array}$ & $\begin{array}{l}\text { Alice Howland, uma linguista de sucesso, é diagnosticada } \\
\text { com Alzheimer aos } 50 \text { anos. A obra trás a documentação da } \\
\text { evolução médica e do quadro clínico da Alice e a preocupação } \\
\text { com o futuro dos seus filhos, inclusive genética. }\end{array}$ \\
\hline $\begin{array}{l}\text { Réquiem para um sonho, } \\
2000\end{array}$ & Darren Aronofsky & $\begin{array}{l}\text { Harry Goldfarb e Marion Silver formam um casal apaixonado. } \\
\text { Porém, ambos são viciados em heroína, o que faz com que } \\
\text { repetidamente Harry penhore a televisão de sua mãe para } \\
\text { conseguir dinheiro. Já Sara, mãe de Harry, começa a tomar } \\
\text { pílulas de emagrecimento, receitadas por seu médico. Só que, } \\
\text { aos poucos, Sara começa a tomar cada vez mais pílulas até se } \\
\text { tornar uma viciada neste medicamento. }\end{array}$ \\
\hline
\end{tabular}

Fonte: O autor (2018). 
No segundo momento, utilizamos perguntas norteadoras referentes aos sentimentos, ideias e racionalidades relacionadas à percepção das emoções conquistadas nessa atividade como: Quais os principais aspectos clínicos observados? Como podemos avaliar a relação dos familiares com o paciente? Como podemos observar o cuidado humanizado? Como o profissional deveria agir para resolução das necessidades de saúde dos pacientes? Como podemos avaliar a relação dos pacientes e familiares com as equipes de saúde? Qual o significado do título do filme? Quais os principais aspectos éticos envolvidos? Quais os principais aspectos sociais, culturais e tecnológicos envolvidos? Qual abordagem poderia ser desenvolvida para ampliar o cuidado ao paciente? Quais os grupos farmacológicos, mecanismos de ação e efeitos adversos dos fármacos?

No terceiro momento, ocorreu o compartilhamento dos sentimentos, ideias e emoções. Nesse momento, a todos, foram assegurados espaços de fala dos significados percebidos em construção individual e coletiva a serem respeitados. Essa articulação se apoia no reconhecimento da utilidade dos saberes a serem aprendidos e no favorecimento da transferência desse conhecimento para uma nova situação. Assim, a VE permite o diálogo entre os educandos e o professor-facilitador visando à mediação das situações e aos esclarecimentos de dúvidas.

\section{Oficinas temáticas: Tarja Preta}

Com o objetivo de articular teoria e prática, as oficinas temáticas intituladas de Tarja Preta, foram utilizadas como um recurso oportuno para construir o conhecimento, em busca da resolução de problemas, a partir das ações criativas dos educandos. As oficinas temáticas tiveram a finalidade de atender às seguintes intencionalidades educacionais: aprender conceitos relacionados à psicofarmacologia; vivenciar o trabalho em equipe; construção coletiva dos saberes; executar as atividades em contextos reais; desenvolver a capacidade crítica, criativa e reflexiva na ação realizada e desenvolver tecnologias com o estímulo de aprender a recriar permanentemente. O público que participou das oficinas foram estudantes da área da saúde, profissionais de saúde, professores e funcionários da instituição de ensino.

Os educandos do curso de psicologia foram divididos em grupos de cinco a seis membros, ou seja, grupos pequenos, que possibilitavam ao professor um maior contato com cada estudante, percebendo as potencialidades e fragilidades de cada um deles, podendo intervir, se necessário. A fase de contextualização e propósito das oficinas foi necessária para tomada de consciência dos estudantes em relação à proposta de trabalho, que era direcionar os conteúdos aprendidos em sala de aula com base na estrutura construtivista e lúdica que atingisse o público participante.

O professor-facilitador das oficinas temáticas visou oportunizar o que os estudantes necessitavam aprender, sendo a abordagem centrada no educando e na aprendizagem. Desse modo, foram realizadas pactuações nos encontros previstos para o desenvolvimento das oficinas que incluíram planejamento do projeto de trabalho, produção de dispositivos didático-pedagógicos, apresentações internas (sala de aula) e execução das oficinas. Os trabalhos e técnicas poderiam ser variados dentro da psicofarmacologia e os grupos deveriam propor interação entre os participantes, além de adaptar a linguagem para o público externo.

Foi realizado um arranjo metodológico estratégico denominado "unidades temáticas" com objetivo de permitir a participação do público externo em todas as oficinas. Sendo assim, elas foram organizadas em salas temáticas individualizadas, onde os grupos realizaram as apresentações entre 20 a 30 minutos e um monitor foi responsável por mobilizar os participantes para as demais oficinas temáticas. 


\section{Resultados e discussão}

Ao propor a formação construtivista em psicofarmacologia clínica foram geradas mudanças no processo ensino-aprendizagem para responder às necessidades de uma sociedade que muda permanentemente. Assim, os estudantes foram se adaptando ao ambiente educacional universitário de amadurecimento,

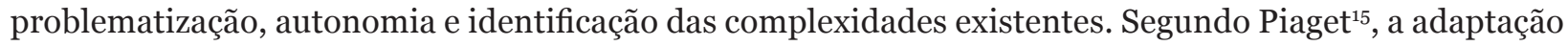
ao meio é função do desenvolvimento da inteligência. A inteligência é assimilação na medida em que incorpora nos seus quadros todo e qualquer dado da experiência ${ }^{15}$. Ou seja, quando é ingressado o novo no conhecido e reduz as noções próprias.

O uso de metodologias ativas permitiu observar a construção do desenvolvimento dos educandos no contexto diário, tendo como resultado uma formação crítica, criativa e reflexiva e com maior tomada de decisões. Dessa maneira, a utilização de ferramentas didáticas ativas no currículo tradicional, possibilitou uma aprendizagem inovadora, gerando o conhecimento a partir do protagonismo dos estudantes. As metodologias ativas ${ }^{15}$ concebem processos interativos de conhecimento, análise, estudos, pesquisa, decisões individuais e coletivas que têm como objetivo encontrar soluções para os problemas de aprendizagem que são apresentados.

A utilização de métodos ativos que não faziam parte da metodologia tradicional foi um grande desafio. Os educandos ficaram, no primeiro momento, surpresos, desconfiados e, posteriormente, animados com a proposta do uso da viagem educacional e oficinas temáticas. Houve necessidade de motivação em alguns momentos quanto à importância desses métodos para a construção do conhecimento e, com o passar do tempo, se tornaram mais habituados, participativos e interessados nas atividades no decorrer do semestre. O processo de ensino e aprendizagem superou as barreiras dos conteúdos com a ampliação do olhar que só pôde ser conquistado pela aceitação e dedicação dos educandos.

Foi essa percepção do processo de ensino-aprendizagem que me motivou a compreender e vivenciar a prática do professor-facilitador. Diante dessa situação, foi articulada a metodologia ativa-participativa com uso da viagem educacional e oficinas temáticas para atribuir as competências necessárias ao perfil profissional do psicólogo. Essa aventura me permitiu observar o despertar dessas competências quando os olhares não eram mais desconfiados e a participação dos educandos se tornava cada vez maior durante as reflexões. Um componente com caráter extremamente biológico baseado em grupos farmacológicos e mecanismos de ação poderia despertar repulsa e, com a pedagogia da facilitação, a condução dos saberes construídos no cotidiano foram ampliados e giravam em torno da prática biopsicossocial.

A viagem educacional permitiu o encanto denovas experimentações que possibilitaram o desenvolvimento do olhar ampliado no cuidado em saúde dentro da psicofarmacologia clínica. Os disparadores permitiram que os educandos construíssem diversos significados, em que as relações familiares, a clínica ampliada e os aspectos farmacológicos predominavam nas discussões (Quadro 2).

A VE permitiu refletir sobre as práticas em saúde levando em consideração a apropriação de conceitos e condutas adotadas por profissionais e usuários dos serviços. Considerando o fator biopsicossocial e a formação profissional em saúde, essa ferramenta, apoiada em uma disciplina de caráter biológico, permitiu humanizar e levar em consideração a subjetividade das dimensões humanas. O cuidado em saúde foi ampliado através dos significados percebidos, que refletiam que a família deveria ser vista como corresponsável pela saúde de seus membros, necessitando ser ouvida, valorizada e estimulada a participar do processo de cuidar. Esse fator é extremamente relevante, pois na maioria das vezes ela não recebe o suporte adequado dos profissionais de saúde. Um significado bastante interessante presente nos diálogos foi o da clínica ampliada ${ }^{16}$, que consiste em ampliar o objeto, agregando a ele, além das doenças, também os problemas de saúde que se encontrem em situações que ampliam o risco ou vulnerabilidade das pessoas. 
Quadro 2 - Significados percebidos pelos educandos de psicologia durante a viagem educacional

\begin{tabular}{|l|l|}
\hline Obras cinematográficas & Significados percebidos \\
\hline Delírios de loucura & $\begin{array}{l}\text { Relação com as equipes de saúde; relações familiares; } \\
\text { descobertas científicas; ética profissional; sanidade } \\
\text { mental; dependência química; clínica ampliada e aspectos } \\
\text { farmacológicos }\end{array}$ \\
\hline Sem limite & $\begin{array}{l}\text { Busca de drogas milagrosas para alteração de estado } \\
\text { da consciência; dependência química e aspectos } \\
\text { farmacológicos }\end{array}$ \\
\hline Geração Prozac & $\begin{array}{l}\text { Relações familiares; conflitos pessoais; uso de drogas e } \\
\text { aspectos farmacológicos }\end{array}$ \\
\hline Uma mente brilhante & $\begin{array}{l}\text { Relações familiares; superação; clínica ampliada; aspectos } \\
\text { clínicos e farmacológicos }\end{array}$ \\
\hline Tempo de despertar & $\begin{array}{l}\text { Relação profissional-paciente; descobertas científicas; } \\
\text { clínica ampliada; humanização; superação; relações } \\
\text { familiares; ética profissional e aspectos farmacológicos }\end{array}$ \\
\hline Para sempre Alice & $\begin{array}{l}\text { Relações familiares; clínica ampliada; suicídio e aspectos } \\
\text { farmacológicos }\end{array}$ \\
\hline
\end{tabular}

Fonte: O autor (2018).

A clínica se torna ampliada ${ }^{16}$ quando é dada autonomia ao indivíduo, comunidade, família, e compartilhada quando há comunicação entre os profissionais de saúde, levando em consideração as suas habilidades e lidando com pessoas na sua dimensão social e subjetiva. Para a construção desses conceitos de autonomia e autocuidado é importante que todos os atores se tornem corresponsáveis pela necessidade de saúde dos pacientes/usuários. Os significados percebidos pelos educandos na VE permitiram o desenvolvimento da aprendizagem significativa através da vivência e da formação construtivista da psicofarmacologia em uma perspectiva clinica ampliada. Existem duas condições para a construção da aprendizagem significativa ${ }^{17,18}$ : a existência de um conteúdo potencialmente significativo e a adoção de uma atitude favorável à aprendizagem, nesse caso, a postura dos educandos que permitiu estabelecer associações entre os elementos novos conquistados em sala e aqueles já presentes na sua estrutura cognitiva.

Durante o processo da facilitação, percebeu-se a importância desse método na construção do conhecimento a partir da razão-emoção, e quando nos víamos discutindo sobre fármacos, mecanismos de ação e efeitos adversos, frequentemente, refletíamos sobre as aventuras que os medicamentos poderiam sofrer em diferentes núcleos familiares e suas consequências. Nesse momento, permitia que os educandos deixassem as ideias fluírem e me saboreava a cada instante com o aprendizado. A experimentação permitia a interpretação de diferentes realidades e análise da diversidade cultural da sociedade, tornando-se uma importante ferramenta didático-pedagógica que facilitou o aprendizado, deixando o ambiente em sala de aula extremamente agradável, por permitir entreter e formar. A VE foi muito rica por tornar espaços de diálogos flexíveis, livres de tensão e estresse, sem descuidar da intencionalidade educacional, colaborando para a construção da inteligência emocional.

A inteligência emocional ${ }^{19}$ passou a ser descrita como detentora das seguintes habilidades básicas e interdependentes: a) autoconsciência: possibilita ao indivíduo perceber, observar, discriminar e nomear seus 
próprios sentimentos; b) automotivação: referente à competência de criar metas para si mesmo, mantendo-se entusiasmado com os objetivos pessoais; c) autocontrole: corresponde à capacidade de desenvolver competências pessoais e administrar sentimentos com intuito de alcançar metas anteriormente estipuladas; d) empatia: por meio da leitura e compreensão de expressões não verbais, o sujeito empático percebe de forma acurada os sentimentos dos outros e e) sociabilidade: refere-se à capacidade de iniciar, manter e aprofundar relações sociais.

As oficinas temáticas se caracterizam como uma estratégia do fazer pedagógico, em que o espaço de construção e reconstrução do conhecimento recebe as principais ênfases ${ }^{13}$. Esse tipo de ferramenta proporcionou aprendizagens mais complexas para se trabalhar com a resolução de problemas, pois valorizou a construção do conhecimento de forma participativa e questionadora, baseada em situações do cotidiano dos estudantes. As oficinas possibilitaram a produção criativa de dispositivos relacionados à doença de Parkinson, depressão, ao Alzheimer, ao TDAH, à esquizofrenia e às drogas de abuso. Os dispositivos construídos foram: banners, folders, caixas de medicamentos, cápsulas de isopor, neurônios em biscuit, demonstrando uma situação normal e patológica, jogo da memória, teatro para identificação dos sintomas nos transtornos mentais e brindes temáticos.

Os brindes temáticos e o teatro relacionado aos transtornos mentais possibilitaram aos educandos a aproximação com os participantes com a intenção de haver a reflexão e vivência relacionada ao acolhimento e vínculo. Merhy ${ }^{20}$ afirma que o acolhimento é a relação humanizada, acolhedora, que os trabalhadores e o serviço, como um todo, têm de estabelecer com os diferentes usuários. Dessa forma, esses dispositivos permitiram que os estudantes percebessem a aproximação das relações clínicas das práticas de saúde ${ }^{21,22}$. Por outro lado, os banners, folders, caixas de medicamentos, cápsulas de isopor, neurônios em biscuit e jogo da memória foram utilizados para aproximar os conhecimentos da psicofarmacologia de forma lúdica, estabelecendo uma comunicação de fácil compreensão aos participantes. O processo comunicativo pode se definir como atitudes de sensibilidade, aceitação e empatia entre os sujeitos. Nesse processo, é relevante o interesse pelo outro, a clareza da transmissão da mensagem e o estabelecimento de relações terapêuticas ${ }^{23}$.

As oficinas temáticas Tarja Preta foram propostas através do conceito de quetoda aprendizagem significativa ${ }^{18}$ envolve o educando como um todo, ou seja, cognitivamente, afetivamente e socialmente, possibilitando a compreensão dos conteúdos, participação do processo, e assim transferir a aprendizagem para outras situações que vivenciar. Tanto a organização das oficinas quanto o material lúdico exposto possuíam uma qualidade expressiva que foi destacada pelos participantes. As oficinas permitiram que fossem exploradas formas de orientar e esclarecer dúvidas, e esse fato colaborou para que esse tipo de estratégia se tornasse assertiva por desenvolver competências ${ }^{22}$ como liderança, planejamento, execução, comprometimento, responsabilidade, satisfação, interesse, capacidade de trabalhar em grupo, problemas reais e construção coletiva do conhecimento.

Nas aventuras por uma formação construtivista em psicofarmacologia clínica, a interdisciplinaridade se tornou um movimento articulador no processo ensino-aprendizagem, tornando-a ampliada. As experimentações aqui descritas superam a visão fragmentada na relação saúde-doença-cuidado e nos processos de produção e socialização do conhecimento. Para Freire ${ }^{24}$, a interdisciplinaridade é o processo metodológico de construção do conhecimento com base em sua relação com o contexto, com a realidade, com sua cultura. De todo modo, o professor precisa tornar-se um profissional com visão integrada da realidade e apropriar-se, também, das múltiplas relações conceituais que sua área de formação estabelece com outras ciências ${ }^{25}$.

As experiências vividas possibilitaram a avaliação do meu próprio desempenho profissional como educador, sentindo-me autor e ao mesmo tempo ator de uma ação, desafiando e sendo desafiado. E esse ato de ser reflexivo quanto a essas ações colaborou para permitir outro sentido para a minha práxis pedagógica. Nesse sentido, Alves ${ }^{26}$ descreve o educador, afirmando que ele valoriza a interioridade na relação com o estudante, suas paixões, esperanças, tristezas, sonhos e história. Já Freire ${ }^{27}$ afirma que o educador formador permite uma prática educativa viva, alegre, afetiva com todo rigor científico e técnico, mas sempre em busca da transformação. 


\section{Considerações finais}

A partir da educação construtivista foi possível utilizar práticas pedagógicas que abriram horizontes e possibilidades de transformação. A prática pedagógica voltada para os princípios da liberdade, problematização e autonomia permitiu que os educandos se tornassem protagonistas da aprendizagem e construíssem as suas histórias através da reflexão. A viagem educacional permitiu o encanto de novas experimentações e possibilitou o conhecimento da psicofarmacologia em uma perspectiva clínica ampliada no cuidado em saúde. Os significados percebidos com a utilização das obras cinematográficas permitiram o desenvolvimento da prática biopsicossocial, de humanização e da construção da inteligência emocional. As oficinas temáticas proporcionaram aprendizagens complexas e a produção de dispositivos que permitiram a vivência do acolhimento, vínculo, comunicação, sensibilidade e empatia entre os sujeitos. A utilização dessas ferramentas foi assertiva por estimular a formação por meio de competências, interdisciplinaridade e aprendizagem significativa, além de tornar o ambiente em sala de aula agradável e contribuir para construção de um perfil profissional que cria permanentemente.

\section{Referências}

1. Becker F. A origem do conhecimento e a aprendizagem escolar. Porto Alegre: Artmed; 2003.

2. Costa CRBSF, Siqueira-Batista R. As teorias do desenvolvimento moral e o ensino médico: uma reflexão pedagógica centrada na autonomia do educando. Rev Bras Edu Méd [Internet]. 2004 [citado em 2018 nov. 07];28(3):242-50. Disponível em: https://goo.gl/e1zKUV

3. Roger C. Liberdade de aprender em nossa década. 2 ed. Porto Alegre: Artes Médicas; 1986.

4. Berbel NAN. A problematização e a aprendizagem baseada em problemas. Interface Comum Saúde Educ [Internet].1998 [citado em 2018 nov. 07];2:139-54. doi: http://dx.doi.org/10.1590/S1414$\underline{32831998000100008}$

5. Brasileiro TSAB, Souza MPR. Psicologia, diretrizes curriculares e processos educativos na Amazônia: um estudo da formação de psicólogos. Rev Sem Assoc Bras Psicol Esc Educ [Internet]. 2010 [citado em 2018 nov. 07];14(1):105-20. Disponível em: www.scielo.br/pdf/pee/v14n1/v14n1a12

6. Freire P. Pedagogia da autonomia: saberes necessários à prática educativa. 33 ed. São Paulo: Paz e Terra; 2006.

7. Mourthé Junior CA, Lima VV, Padilha RQ. Integrating emotions and rationalities for the development of competence in active learning methodologies. Interface (Botucatu) [Internet]. 2018 [citado em 2018 nov. 07];22(65):577-88. Disponível em: http://dx.doi.org/10.1590/1807-57622016.0846

8. Guilhem D, Diniz D, Zicker F. Pelas lentes do cinema: bioética e ética em pesquisa, Brasília: Letras Livres, UnB; 2007.

9. Bossemeyer D, Moura ERF. Formação de formadores: manual de referência (revisão e adaptação para o programa de apoio à prevenção do HIV/SIDA. Baltimore: JHPIEGO, Johns Hopkins University; 2006.

10. Farré $M$, Bosch F, Roset PN, Baños JE. Putting clinical pharmacology in context: the use of popular movies. J Clin Pharmacol [Internet]. 2004 [citado em 2018 nov. 07];44(1):30-6. doi: https://doi. org/10.1177/0091270003260679

11. Gallagher P, Wilson N, Edwards R, Cowie R, Baker MG. A pilot study of medical student attitudes to, and use of, commercial movies that address public health issues. BMC Research Notes [Internet]. 2011 [citado em 2018 nov. 07];4(7):111. doi: https://doi.org/10.1186/1756-0500-4-111

12. Santos SN; Noro A. O uso de filmes como recurso pedagógico no ensino da neurofarmacologia. Interface (Botucatu) [Internet]. 2013 [citado em 2018 nov. 07];17(46):705-14. doi: http://dx.doi. org/10.1590/S1414-32832013005000021

13. Anastasiou LGC, Alves LP. Estratégias de ensinagem. In: Anastasiou LGC, Alves L P. Processos de ensinagem na universidade: pressupostos para as estratégias de trabalho em aula. 3 ed. Joinville: Univille; 2004. p. 67-100. 
14. Nascimento MS. Oficinas pedagógicas: Construindo estratégias para a ação docente - relato de experiência. Rev Saúde Com [Internet]. 2007 [citado em 2018 nov. 07];3(1):85-95. Disponível em: http://www.uesb.br/revista/rsc/ojs/index.php/rsc/article/view/65

15. Piaget J. O Nascimento da inteligência na criança. 2.ed. Rio de Janeiro: Zahar; 1975.

16. Daltro MR, Ponde MP. Aprendizagem baseada em problemas: uma estratégia para formação do psicólogo como profissional de saúde. Rev Psic Divers e Saúde [Internet]. 2017 [citado em 2018 nov. 07];6(2):103-13. doi: http://dx.doi.org/10.17267/2317-3394rpds.v6i2.1391

17. Campos GWS, Amaral MA. A clínica ampliada e compartilhada, a gestão democrática e redes de atenção como referenciais teórico-operacionais para a reforma do hospital. Ciênc. saúde coletiva [Internet]. 2007 [citado em 2018 nov. 07];12(4):849-59. doi: http://dx.doi.org/10.1590/S1413-81232007000400007

18. Moreira MA. Aprendizaje significativo: teoria y práctica. Madrid: Visor; 2000.

19. Mayer JD, Salovey P. What is emocional intelligence? In: Salovey P, Sluyter DJ, organizadores. Emotional development and emocional intelligence: Educational implications. New York: Basic Books; 1997. p. 3-31.

20. Merhy EE. Em busca da qualidade dos serviços de saúde: os serviços de porta aberta para a saúde e o modelo tecnoassistencial em defesa da vida (ou como aproveitar os ruídos do cotidiano dos serviços de saúde e colegiadamente reorganizar o processo de trabalho na busca da qualidade das ações de saúde). In: Cecílio LCO, organizador. Inventando a mudança em saúde. São Paulo: Hucitec; 1994. p.117-60.

21. Franco TB, Bueno WS, Merhy EE. O acolhimento e os processos de trabalho em saúde: o caso de Betim, Minas Gerais, Brasil. Cad Saúde Pública [Internet]. 1999 [citado em 2018 nov. 07];5(2):345-53. doi: http://dx.doi.org/10.1590/S0102-311X1999000200019

22. Mattos MP. Metodologias ativas auxiliando no aprendizado das ciências morfofuncionais numa perspectiva clínica: um relato de experiência. Rev. Ciênc. Médicas Biológicas [Internet]. 2017 [citado em 2018 nov. 07];16(2):146-50. doi: http://dx.doi.org/10.9771/cmbio.v16i2.20159

23. Braga EM, Silva MJP. Comunicação competente: visão de enfermeiros especialistas em comunicação. Acta Paul Enf [Internet]. 2007 [citado em 2018 nov. 07];20(4):410-4. doi: http://dx.doi.org/10.1590/ $\underline{\text { S0103-21002007000400004 }}$

24. Freire P. Pedagogia do oprimido. Rio de Janeiro: Paz e Terra, 1987.

25. Thiesen JS. A interdisciplinaridade como um movimento articulador no processo ensino-aprendizagem. Rev Bras Educ [Internet]. 2008 [citado em 2018 nov. 07];13(39):545-54. doi: http://dx.doi.org/10.1590/ $\underline{\mathrm{S} 1413-24782008000300010}$

26. Alves R. Conversas com quem gosta de ensinar. São Paulo: Cortes; 1988.

27. Freire P. Educação e mudança. São Paulo: Paz e Terra; 1999. 